\section{Patients with familial non-medullary thyroid cancer have an outcome similar to that of patients with sporadic papillary thyroid tumors}

\author{
Pacientes com câncer não medular familiar da tiroide têm \\ evolução similar aos portadores de câncer papilífero esporádico
}

Fabián Pitoia', Graciela Cross', María E. Salvai', Erika Abelleira', Hugo Niepomniszcze'
1 Division of Endocrinology, Hospital de Clinicas, University of Buenos Aires, Buenos Aires, Argentina
Correspondence to: Fabián Pitoia

Division of Endocrinology, Hospital de Clinicas, University of Buenos Aires Av. Córdoba, 2351, $5^{\circ}$ piso, 1120 - Buenos Aires, Argentina fpitoia@intramed.net

Received on Dec/1/2010 Accepted on Feb/7/2011

\section{INTRODUCTION}

$\mathrm{R}$ obinson and Orr were the first to describe cases of papillary thyroid cancer in monozygotic twins (1).
After their presentation, many studies have provided enough evidence to show genetic predisposition to this entity and many authors have called it familial non-medullary thyroid cancer (FNMTC) (2-5). 
To consider this diagnosis, two or more members of the same family must be affected by papillary thyroid cancer (PTC). However, because of the current high prevalence of thyroid cancer, there is some controversy regarding the true incidence of FNMTC, especially in families with only two affected members $(5,6)$.

FNMTC is often categorized into two groups: the first group comprises all the syndromic cases, such as: familial adenomatous polyposis, Gardner's syndrome, Cowden disease, Werner's syndrome, and Carney's complex, among others (6). The second group accounts for the FNMTC cases not included into any hereditary syndrome. Prevalence is estimated at about 5\% of all PTC (7-9).

An autosomal dominant mode of inheritance with variable penetrance is likely to appear in most large FNMTC pedigrees (2). Polygenic inheritance is also plausible, especially in those cases of only two affected family members or related to carcinogenic events like radiation exposure (10).

The clinical characteristics of FNMTC are controversial. Some, but not all authors have shown an earlier age of onset, higher incidence of multifocality and lymph node metastasis, and a more aggressive outcome with more frequent relapses $(4,5,11-13)$. It has also been recently shown that FNMTC displays the features of clinical 'anticipation' with the second generation acquiring the disease at an earlier age and with more advanced disease at presentation (13).

The aim of this study was to compare the clinical behavior and the outcome of 16 subjects with FNMTC from seven unrelated kindred with those observed in 160 subjects with non familial PTC from our databases.

\section{SUBJECTS AND METHODS}

We retrospectively reviewed, after informed consent was obtained in accordance with the local Ethical Committee guidelines, the clinical records of all sporadic papillary thyroid cancer (SPTC) patients $(n=160)$ followed in the Division of Endocrinology, Hospital de Clínicas - University of Buenos Aires (Argentina) from 1994 to 2008. Papillary thyroid carcinoma accounted for $91 \%$ of our entire differentiated thyroid carcinoma database. We evaluated the clinical-pathological features of FNMTC and SPTC patients, including gender, age at diagnosis, tumor size, histology (variants), presence of multicentricity and bilaterality, rate of lymph node metastases, and outcome in the follow-up.
FNMTC was defined according to the presence of 2 or more cases of DTC in one family, after excluding the syndromic cases, as previously reported (13).

FNMTC was found in 16 subjects from 7 kindred (16/176, $9 \%$ of the entire group with papillary thyroid cancer diagnosis). None of the included subjects had been exposed to radiation. In $8 / 16$ subjects (50\%) with FNMTC diagnosis was made after a screening process performed due to the previous diagnosis of thyroid cancer in their relatives. The pedigree of the included FNMTC subjects is observed in figure 1 .

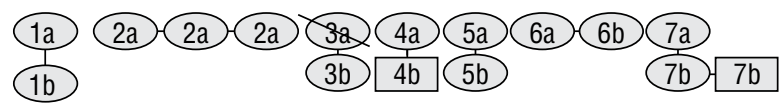

Figure 1. Pedigree of patients with familial non-medullary thyroid cancer (FNMTC) included in the study. $\bigcirc$ Female $\square$ Male; Strikethrough bar: death; Vertical axis: mother/daughter-son; Horizontal axis: brothers/ sisters.

All included subjects had received total thyroidectomy and radioiodine ablation (100-150 mCi 131-I). Lymph node dissection had been performed in 10/16 (62\%) patients of the FNMTC group and in 71/160 $(44.3 \%)$ patients of the SPTC group ( $\mathrm{p}=0,01)$. Lymph nodes were dissected when metastatic intrasurgical anatomopathological analysis proved the presence of metastasis (frozen section). This was true for $3 / 10(30 \%)$ patients of the FNMTC Group and for 32/71 (45\%) patients of the SPTC Group. In the remaining patients from the FNMTC Group $(\mathrm{n}=7,70 \%)$ and SPTC $(\mathrm{n}=$ $39,54.9 \%$ ) Group, lymph node dissections in the central neck compartment (level VI) was mostly indicated after original tumor size (T3) and/or suspicious lymph nodes were noted during surgical procedure. A greater frequency of prophylactic lymph node dissections in the VI compartment, performed in the FNMTC Group, was probably indicated due to the knowledge of the familial background of thyroid neoplasia.

Mean time of follow-up was of $87 \pm 41$ months (range: 48 to 144 months) in the FNMTC Group and $82 \pm 39$ months (range 27 to 167 months) in the SPTC Group $(\mathrm{p}=\mathrm{ns})$.

We defined the outcome according to the most recent guidelines of the Thyroid Societies $(14,15)$. The "free of disease status" was considered when an undetectable stimulated thyroglobulin $(\mathrm{Tg})$ level $(\leq \mathrm{lng} / \mathrm{mL})$ was associated to negative anti-thyroglobulin antibodies (Tg-Ab). In high risk patients, the negative post-dose body scan (in general, doses higher than $100 \mathrm{mCi}$ 
131-I) was also considered to report that the patient was cured. Ultrasonography (US) without suspicious findings, performed twice a year in all cases, was also required to define the free of disease status. Persistence of disease: Detectable Tg levels under thyroid hormone suppressive therapy and/or stimulated $\mathrm{Tg}$ levels greater than $2 \mathrm{ng} / \mathrm{mL}$ and/or demonstrated metastatic disease (US, CT, MRI, positive WBS, PET-CT Scan, etc.). If the stimulated $\mathrm{Tg}$ level was between 1 and $2 \mathrm{ng} / \mathrm{mL}$, it could not be assumed that there was a persistent disease until a new stimulated test was repeated 6 to 12 months later to corroborate the tendency of the $\mathrm{Tg}$ level. A stimulated Tg level between 1 and $2 \mathrm{ng} / \mathrm{mL}$ could have been indicative of incomplete ablation, insufficient time to render undetectable, or persistent disease. However, this situation (stimulated Tg level between $\mathrm{l}$ and $2 \mathrm{ng} / \mathrm{mL}$ ) was not observed in any of our patients.

In the follow-up, recurrences were classified as: lymph node metastasis (confirmed by a FNAB with positive cytology), distant metastasis (confirmed by CT/positive WBS/PET-CT, etc.), local recurrence (recurrent tumor in thyroid bed), and unknown site (stimulated Tg levels above $2 \mathrm{ng} / \mathrm{mL}$ ).

$\mathrm{Tg}$ stimulation was performed after the usual dose administration of recombinant human TSH (rhTSH, Genzyme Corp, MA) in 2/16 patients of the FNMTC Group and in 19/160 patients of the SPTC Group. The remaining patients were evaluated for at least three weeks after thyroid hormone withdrawal.

\section{Statistical analysis}

All data are presented as mean \pm S.D. and medians when appropriate. To compare the statistical differences between the variables of two independent groups where the condition of normality is not satisfied, the Mann-Whitney U test was used. To assess the association among qualitative variables, the Fisher's or $\mathrm{X}^{2}$ tests were used. The observed differences were assumed statistically significant if the probability of chance occurrence was less than $5 \%(\mathrm{P}<0.05)$.

\section{RESULTS}

\section{Baseline characteristics at diagnosis}

The clinical features of FNMTC $(\mathrm{n}=16)$ compared to sporadic cases are shown in table 1 . In patients with FNMTC, mean age at diagnosis was $41.7 \pm 13$ vs. 44 \pm 16 years in the sporadic group $(\mathrm{p}=\mathrm{ns})$. The female $/$ male ratio was $7 / 1$ vs. $6 / 1$, respectively $(\mathrm{p}=\mathrm{ns})$. We did not find any statistically significant difference when the tumor size, histological variant of PTC, stage (American Joint Committee on Cancer - AJCC, $6^{\text {th }}$ Edition $)$ and distant metastasis at onset were analyzed (Table 1).

Table 1. Baseline characteristics in patients with familial non-medullary thyroid cancer (FNMTC) vs. sporadic papillary thyroid cancer (SPTC). F/M: Female/Male ratio. AJCC 6 (American Joint Committee on Cancer, $6^{\text {th }}$ Edition)

\begin{tabular}{lccc}
\hline \multicolumn{1}{c}{ Characteristic } & FNMTC (n= 16) & SPTC ( $\mathbf{n = 1 6 0 )}$ & $\mathbf{p}$ \\
\hline Age at diagnosis & $41.7 \pm 13$ & $44 \pm 16$ & $\mathrm{~ns}$ \\
F/M & $7 / 1$ & $6 / 1$ & $\mathrm{~ns}$ \\
Tumor size at diagnosis & $17 \pm 4 \mathrm{~mm}$ & $18 \pm 5 \mathrm{~mm}$ & $\mathrm{~ns}$ \\
Bilateral disease & $6 / 16(38 \%)$ & $38 / 160(24 \%)$ & 0.03 \\
Multicentricity & $7 / 16(43 \%)$ & $45 / 160(28 \%)$ & 0.03 \\
Classical Papillary & $62.5 \% / 31.2 \% / 6.3 \%$ & $62.3 \% / 31.4 \% / 6.3 \%$ & $\mathrm{~ns}$ \\
thyroid cancer/follicular & & & \\
variant/others (\%) & & & \\
Stage I (AJCC 6) & $9 / 16(56.2 \%)$ & $98 / 160(61.2 \%)$ & $\mathrm{ns}$ \\
Stage II & $1 / 16(6.2 \%)$ & $8 / 160(5 \%)$ & $\mathrm{ns}$ \\
Stage III & $3 / 16(18.8 \%)$ & $31 / 160(19.3 \%)$ & $\mathrm{ns}$ \\
Stage IV & $3 / 16(18.8 \%)$ & $23 / 160(14.5 \%)$ & $\mathrm{ns}$ \\
Lymph node metastasis & $9 / 16(56.2 \%)$ & $62 / 160(39 \%)$ & 0.01 \\
at diagnosis & & & \\
Distant metastasis at & $2 / 16(14 \%)$ & $26 / 160(16 \%)$ & $\mathrm{ns}$ \\
diagnosis & & & \\
\hline
\end{tabular}

However, malignancy was bilateral at diagnosis in $6 / 16(38 \%)$ vs. $38 / 160(24 \%)$, respectively $(\mathrm{p}=0.03)$ and multicentricity was observed in $7 / 16(43 \%) v s$. $45 / 160(28 \%)$, respectively $(\mathrm{p}=0.03)$. Lymph node metastases were diagnosed in $9 / 16(56.2 \%)$ of FNMTC and in $62 / 160(39 \%)$ of sporadic PTC $(\mathrm{p}=0.01)$.

\section{Follow-up outcome}

Mean time of follow-up was $87 \pm 41$ months (range 48 to 144 months) in the FNMTC Group and $82 \pm 39$ months (range 27 to 167 months) in the SPTC Group $(\mathrm{p}=\mathrm{ns})$. The mean radioiodine dose administered in each group was as follows: $159 \pm 82 \mathrm{mCi} 131-\mathrm{I}$ in the FNMTC Group vs. $171 \pm 89 \mathrm{mCi} 131$-I in the SPTC Group $(\mathrm{p}=\mathrm{ns})$. The free of disease status was achieved in 9 patients (56\%) of the FNMTC group and in $86(54 \%)$ of the SPTC Group $(\mathrm{p}=\mathrm{ns})$. Persistent or recurrent disease was observed in a similar percentage of cases in each group ( $38 \%$ vs. $39 \%$, respectively) and disease-related deaths occurred in 1 case $(6 \%)$ of the FNMTC Group and in 11 patients (7\%) of the second group (Figure 2). 


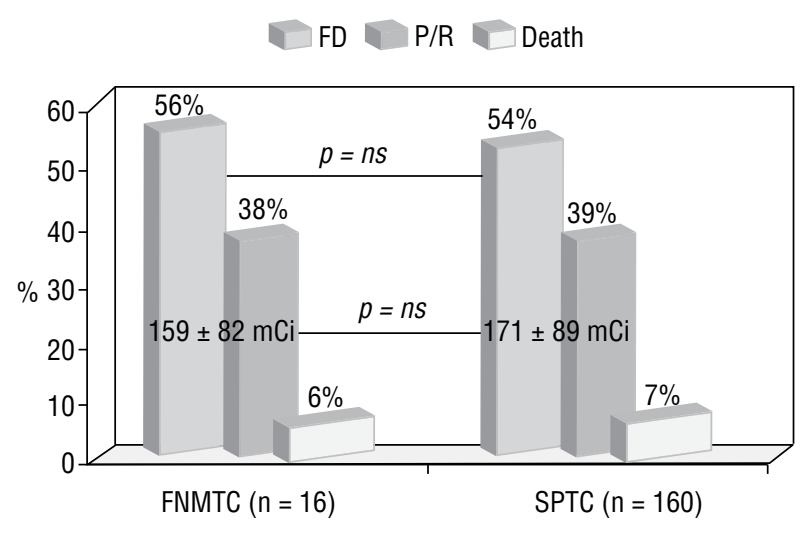

Figure 2. Comparison of outcome in the long-term follow-up of patients with familial non-medullary thyroid cancer (FNMTC) vs. patients with sporadic papillary thyroid cancer (SPTC). FD: Free of disease; P/R: Persistent or recurrent disease. Boxes: Mean \pm SD 131-I dose received by each group.

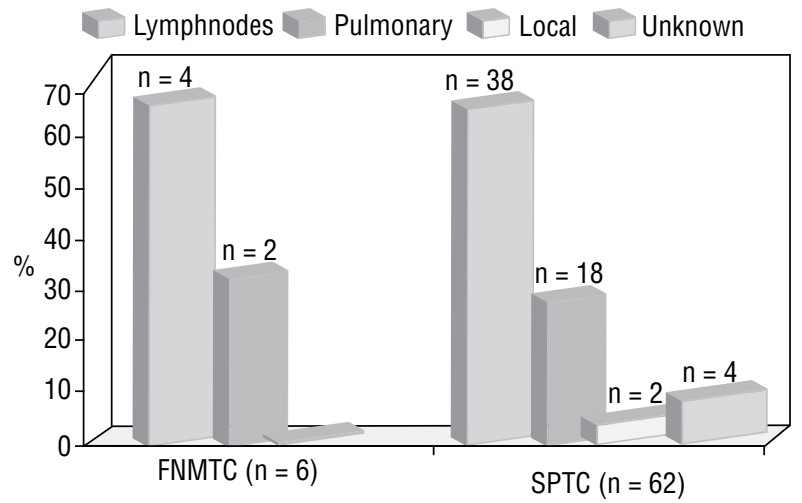

Figure 3. Assessment of metastatic or recurrent sites in patients with familial non-medullary thyroid cancer (FNMTC) vs. sporadic papillary thyroid cancer (SPTC).

In spite of the limited number of patients with persistent/recurrent disease in the FNMTC Group ( $\mathrm{n}=$ $6)$, we compared the metastatic sites between groups. We observed that there were no gross differences between groups when the persistent site was considered (Figure 3).

\section{DISCUSSION}

The clinical characteristics of FNMTC are being clarified, not only by family studies, but also by large epidemiologic revisions. The review of different kindred and genetic studies suggests that inheritance is autosomal dominant and that penetrance is incomplete and increases with age (16-19). As with SPTC, women are affected approximately 2 to 3 times more frequently than men (16), and the age of onset of FNMTC may be younger than that for sporadic tumors $(13,19)$.
We have recently performed a clinical analysis in 79 relatives of the 16 patients with FNMTC we are presenting now (20). We evaluated the frequency of thyroid disorders in the first degree relatives of these subjects and we also performed molecular analysis of the FNMTC tumors searching for alterations in ret/ PTC1 to ret/PTC3; for trkA, trkT1, trkT2 and trkT3 rearrangements and for $\mathrm{Ha}$-, $\mathrm{Ki}$ - or $\mathrm{N}$-ras, assessed in DNA of these carcinomas. Clinical screening of the 79 family members showed a higher presence of goiter when compared with a normal population control group $(29 \%$ vs. $8.7 \%, \mathrm{p}<0.001)$ and higher frequency of hypothyroidism $(5 \%$ vs. $2.5 \%, \mathrm{p}<0.01)$. In the molecular analysis, only a proto-oncogene trk rearrangement was observed in 2 subjects of one of the families (20).

Some of the published studies have reported that compared with SPTCs, FNMTCs are usually more aggressive $(12,21)$. However, in discrepancy with these investigations, other authors have shown no differences in the clinical outcome between these two groups of patients $(19,22,23)$. Recently, Robenshtok and cols. (23) published a retrospective analysis of 67 patients with FNMTC who were compared with 375 control subjects with sporadic non-medullary thyroid cancer (not only PTC). They did not find a higher frequency of multicentric disease and lymph node metastases at diagnosis, as we did. However, similarly to our findings, the authors showed FNMTC to have a similar long-term outcome when compared with sporadic disease.

The results observed in our series also seem to be similar to those observed by Capezzone and cols. (13), at least in the clinical characteristics at diagnosis, where there was a marginal trend to greater aggressiveness of FNMTCs which were more frequently multifocal, bilateral, and with increased number of lymph node metastases at presentation. However, this situation seemed not to impact adversely on the outcome of our patients.

One caveat is that the patients with FNMTC in our study did have a more aggressive surgical treatment. This approach may have given a greater incidence of lymph node metastatic disease in the FNMTC group $(56.2 \%$ vs. $39 \%)$. As we can see, the outcome seems to be very similar in both groups of patients; however, we cannot exclude the impact of the initial treatment as a major factor leading to this result.

In conclusion, the bilateral tumor occurrence and the higher frequency of lymph node metastasis at diagnosis were the only differences observed between FNMTC and SPTC. This scenario, although perhaps 
biased by a more aggressive initial surgical treatment, seemed not to alter the compared outcome between these two groups of patients with PTC in the long term follow-up. Although routine total thyroidectomy and probably lymph node dissection in the central neck compartment is recommended for FNMTC, the therapeutic strategy chosen can otherwise be the same as that for SPTC.

Acknowledgements: We want to thank Dr. Laura Ward for her kind help with the translation of the title/abstract into Portuguese.

Disclosure: no potential conflict of interest relevant to this article was reported.

\section{REFERENCES}

1. Robinson DW, OrrTG. Carcinoma of the thyroid and other diseases of the thyroid in identical twins. Arch Surg. 1955;70(6):923-8.

2. Lote K, Andersen K, Nordal E, Brennhovd IO. Familial occurrence of papillary thyroid carcinoma. Cancer. 1980;46(5):1291-7.

3. Ozaki O, Ito K, Kobayashi K, Suzuki A, Manabe Y, Hosoda Y. Familial occurrence of differentiated, nonmedullary thyroid carcinoma. World J Surg. 1988;12(4):565-71.

4. Houlston RS, Stratton MR. Genetics of non-medullary thyroid cancer. Q J Med. 1995;88(10):685-93.

5. Burgess JR, Duffield A, Wilkinson SJ, Ware R, Greenaway TM, Percival J, et al. Two families with an autosomal dominant inheritance pattern for papillary carcinoma of the thyroid. J Clin Endocrinol Metab. 1997;82(2):345-8.

6. Sturgeon $\mathrm{C}, \mathrm{Clark} \mathrm{OH}$. Familial nonmedullary thyroid cancer. Thyroid. 2005;15(6):588-93.

7. Pal T, Vogl FD, Chappuis PO, Tsang R, Brierley J, Renard H, et al. Increased risk for nonmedullary thyroid cancer in the first degree relatives of prevalent cases of nonmedullary thyroid cancer: a hospital-based study. J Clin Endocrinol Metab. 2001;86(11):5307-12.

8. Orsenigo $E$, Beretta $E$, Gini P, Verrecchia F, Invernizzi L, Fiorina $P$, et al. A report of six cases of familial papillary thyroid cancer. Eur $\mathrm{J}$ Surg Oncol. 2003;29(2):185-7.

9. Frich L, Glattre E, Akslen LA. Familial occurrence of nonmedullary thyroid cancer: a population based study of 5673 first degree relatives of thyroid cancer patients from Norway. Cancer Epidemiol Biomarkers Prev. 2001;10(2):113-7.

10. Kazakov VS, Demidchik EP, Astakhova LN. Thyroid cancer after Chernobyl. Nature. 1992;359(6390):21.
11. Takami H, Ozai O, Ito K. Familial nonmedullary thyroid cancer: an emerging entity that warrants aggressive treatment. Arch Surg. 1996;131(6):676.

12. Alsanea O, Wada N, Ain K, Wong M, Taylor K, Ituarte PH, et al. Is familial non-medullary thyroid carcinoma more aggressive than sporadic thyroid cancer? A multicenter series. Surgery. 2000;128(6):1043-51.

13. Capezzone M, Marchisotta S, Cantara S, Busonero G, Brilli L, Pazaitou-Panayiotou $\mathrm{K}$, et al. Familial non-medullary thyroid carcinoma displays the features of clinical anticipation suggestive of a distinct biological entity. Endocr Relat Cancer. 2008;15(4):1075-81.

14. Pitoia F, Ward L, Wohllk N, Friguglietti C, Tomimori E, Gauna A, et al. Recommendations of the Latin American Thyroid Society on diagnosis and management of differentiated thyroid cancer. Arq Bras Endocrinol Metabol. 2009;53(7):884-7.

15. Cooper DS, Doherty GM, Haugen BR, Kloos RT, Lee SL, Mandel $\mathrm{SJ}$, et al. Revised American Thyroid Association management guidelines for patients with thyroid nodules and differentiated thyroid cancer. Thyroid. 2009;19(11):1167-214.

16. Malchoff CD, Sarfarazi M, Tendler B, Forouhar F, Whalen G, Malchoff DM. Familial papillary thyroid carcinoma is genetically distinct from familial adenomatous polyposis coli. Thyroid. 1999;9(3):247-52.

17. Canzian F, Amati P, Harach HR, Kraimps JL, Lesueur F, Barbier $\mathrm{J}$, et al. A gene predisposing to familial thyroid tumors with cell oxyphilia maps to chromosome 19p13.2. Am J Hum Genet. 1998;63(6):1743-8.

18. McKay JD, Lesueur F, Jonard L, Pastore A, Williamson J, Hoffman $L$, et al. Localization of a susceptibility gene for familial nonmedullary thyroid carcinoma to chromosome 2q21. Am J Hum Genet. $2001 ; 69(2): 440-6$.

19. Loh KC. Familial nonmedullary thyroid carcinoma: a meta-review of case series. Thyroid. 1997;7(1):107-13.

20. Cross G, Pitoia F, Suárez $H$, Kral M, Manavela M, Morando $D$, et al. High prevalence of thyroid disorders in relatives of patients with familial papillary thyroid cancer. Medicina (B Aires). 2010;70(2):139-42.

21. Uchino $S$, Noguchi S, Kawamoto $H$, Yamashita $H$, Watanabe $S$, Yamashita $\mathrm{H}$, et al. Familial non-medullary thyroid carcinoma characterized by multifocality and a high recurrence rate in a large study population. World J Surg. 2002;26(8):897-902.

22. Maxwell EL, Hall FT, Freeman JL. Familial nonmedullary thyroid cancer: a matched-case control study. Laryngoscope. 2004;114(12):2182-6.

23. Robenshtok E,Tzvetov G, Grozinsky-Glasberg S, Shraga-Slutzy I, Weinstein R, Lazar L, et al. Clinical characteristics and outcome of familial nonmedullary thyroid cancer: a retrospective controlled study. Thyroid. 2011;21(1):43-8. Epub 2010 Oct 18. 